\title{
NOVOS OLHARES PARA O ENSINO DE QUÍMICA E AMBIENTE NA EDUCAÇÃO DE JOVENS E ADULTOS
}

Thiago Rodrigues de Sá Alves

Rose Mary Latini

\section{Introdução}

No Brasil, a história da Educação de Jovens e Adultos (EJA) é voltada para aqueles estudantes que não tiveram, por algum motivo, acesso à escolarização em período regular. Essa modalidade de ensino está bastante ligada aos estudos e pensamentos de Paulo Freire, que, durante os anos 1960, já apontava para a necessidade de uma educação problematizadora, capaz de superar uma educação bancária (FREIRE, 2002).

Os pensamentos do autor nos fazem recordar toda uma discussão envolvendo a formação de nossos alunos e como nós, professores, podemos e devemos respeitar os saberes de vida trazidos pelos estudantes para dentro de sala de aula por meio de temáticas que possam "discutir, por exemplo, a poluição dos riachos e dos córregos e os baixos níveis de bem-estar das populações, os lixões e os riscos que oferecem as saúdes das gentes" 
(FREIRE, 2002, p. 15). Diante disso, o professor deve ter o cuidado de saber encontrar estratégias efetivas para trabalhar essa vivência deles relacionadas aos conteúdos que serão ensinados.

A motivação para lançarmos novos olhares para o Ensino de Química na EJA está ligada ao fato de o primeiro autor deste trabalho ter atuado como professor dessa modalidade de ensino e vivenciado muitas das inquietações que perpassam tanto a prática docente, como as expectativas dos alunos. Tais inquietações transcorrem desde as constantes mudanças nas propostas estaduais para a EJA e envolvem a baixa problematização dos conteúdos de química, em que prevalecem práticas que têm por base apenas o conteúdo científico, o baixo aproveitamento dos alunos e até o relato das dificuldades dos estudantes para permanecerem na EJA, cabendo ressaltar que algumas dessas dificuldades/obstáculos também são encontradas em outras modalidades de ensino.

A partir dessas inquietações, fomos levados a reflexões sobre as possibilidades da prática docente nesse cenário e ao desejo de inserir propostas que possam aproximar os conceitos científicos construídos nas práticas de Ensino de Química da realidade vivida dos sujeitos escolares, de forma a favorecer não somente o aprendizado de química, mas também uma leitura de mundo, em especial do que é ligado às questões ambientais, que, no 
cenário de crise hoje vivenciada, necessita de maior compreensão.

Procuramos, então, nos aprofundar sobre questões afetas a esta modalidade de ensino, inicialmente por meio de uma atividade diagnóstica que nos mostrou que as turmas em que o autor trabalhou apresentavam alunos com idade entre 20 e 66 anos, em que muitos deles, em seus diálogos, relatavam que as limitações faziam parte de seu cotidiano, mas que tentavam, a todo instante, solucioná-las, já que tinham muita força de vontade. Essa interlocução realizada com os alunos também proporcionou perceber que eles manifestavam um sentimento de medo de não concluírem a EJA pelos mesmos motivos que muitos deles abandonaram, anteriormente, a escola. De acordo com Fonseca muitos deixam a escola

para trabalhar; deixam a escola porque as condições de acesso e segurança são precárias, deixam a escola porque os horários e as exigências são incompatíveis com a responsabilidade que se viram obrigados a assumir. Deixam a escola porque não há vaga, não tem professor, não tem material. Deixam a escola, sobretudo, porque não consideram que a formação escolar seja assim tão relevante que justifique enfrentar toda essa gama de obstáculos à sua permanência ali. (FONSECA, 2007, p. 32-33).

Diante desses fatos, ficou ainda mais claro o papel fundamental do professor na EJA, que, além do com- 
promisso de precisar destacar o potencial de seus alunos, necessita também

\begin{abstract}
[...] compreender a necessidade de respeitar a pluralidade cultural, as identidades, as questões que envolvem classe, raça, saber e linguagem dos seus alunos, caso contrário, o ensino ficará limitado à imposição de um padrão, um modelo pronto e acabado em que se objetiva apenas ensinar a ler e escrever, de forma mecânica (LOPES; SOUZA, 2007, p. 13-14).
\end{abstract}

Nesse cenário, foi possível observar, no estado do Rio de Janeiro, em um espaço de tempo relativamente curto, muitas mudanças ocorridas em diferentes momentos.

Até o ano de 2012, a EJA era ofertada pelo governo do Estado do Rio de Janeiro em três fases - Fases I, II e III - e os alunos se formavam no tempo de um ano e meio, a disciplina de química era trabalhada em dois tempos semanais de quarenta minutos (RIO DE JANEIRO, 2009). Nesse período, os professores que atuavam nessa modalidade tinham como diretriz a Reorientação Curricular, proposta pela SEEDUC em 2006, a qual apresentava orientações para que os docentes desenvolvessem o conteúdo de química nas diferentes fases da EJA. De acordo com a Reorientação Curricular, o aspecto comum das propostas de ensino apresentadas 
[...] é a preocupação com estudos que partam de vivências, de indagações, de curiosidade diante dos fenômenos da natureza e das grandes questões filosóficas e transportem o educando para novas situaçõesproblema nas quais novas perguntas aparecem, novos modelos se fazem necessários, novas respostas são dadas. Esses estudos não se apresentam, portanto, descontextualizados, mas, ao contrário, refletem preocupações atuais, com enfoques a partir de conhecimentos modernos e pertinentes às experiências dos alunos, pensamento que guia todos os módulos das diferentes disciplinas. (RIO DE JANEIRO, 2006, p. 79).

No ano de 2013, foi criado o currículo mínimo da EJA, sendo que, nesse mesmo ano, ocorreu, quase que paralelamente, a implementação de uma nova política de educação para os jovens e adultos intitulada Ensino Médio Programa Nova EJA, que conta com a parceria do próprio Estado e da Fundação Centro de Ciências e Educação Superior a Distância do Estado do Rio de Janeiro CECIERJ. A proposta curricular da Nova EJA é bem próxima do Currículo Mínimo/RJ, com pequenas diferenças, principalmente em relação ao conteúdo de Química Orgânica ${ }^{1}$. O programa possui uma proposta de metodologia que busca

${ }^{1} \mathrm{O}$ currículo do Ensino Médio Regular, no $4^{\mathrm{o}}$ bimestre, aborda a temática referente às Biomoléculas e aos Polímeros, possibilitando ao aluno ter a compreensão do que são os polímeros e como identificálos nos plásticos e em biomoléculas. Daí a importância de se destacar os carboidratos, proteínas e ácidos nucleicos. O currículo da EJA 
valorizar a experiência de cada aluno, que é visto como sujeito construtor de conhecimento, e a própria experiência de vida adquirida na educação extraescolar é o ponto de partida e referencial permanente para outras aprendizagens. Essa nova metodologia representa uma promessa de confirmar um caminho de desenvolvimento de todas as pessoas, de todas as idades. Dessa forma, essa nova proposta poderá atingir seu objetivo maior: construir uma sociedade mais justa, mais desenvolvida, mais igualitária e humana (RIO DE JANEIRO, 2015, p. 4).

Apesar de todos esses documentos sinalizarem uma preocupação em se "valorizar a experiência do aluno", na prática, o que observamos é que tantas mudanças acabam por contribuir para gerar incertezas sobre os propósitos da EJA. Ou, quem sabe, apontam para a pouca valorização dessa modalidade de ensino nas propostas governamentais, haja vista a própria Base Nacional Comum Curricular (BNCC) não dedicar um capítulo ou mesmo uma parte do seu documento a essa modalidade de ensino. Um estudo recente feito por Moraes, Cunha e Voigt (2019) sobre a EJA relata que na "nova Base Nacional Curricular Comum, a EJA é tratada da mesma forma que toda a educação fundamental, inserida na educação

opta por discutir a temática dos combustíveis e alimentos. Acerca deste último item, podemos observar que o documento busca conscientizar sobre a relação do consumo de anabolizantes, medicamentos, açúcares, dentre outros exemplos. 
básica. Essa modalidade é mencionada apenas nas leis gerais como a LDB e Diretrizes Curriculares Nacionais" (MORAES; CUNHA; VOIGT, 2019, p. 12).

O que nos chama atenção é a ausência, nesse documento, de qualquer texto que problematize a EJA e busque romper com a dominação de grupos já marginalizados pela sociedade e que devem ter a possibilidade de ter suas histórias e culturas reconhecidas e representadas (SILVA, 1999; MOREIRA, 2001; CANDAU, 2008).

Podemos dizer que a BNCC se mostra inadequada ao púbico da EJA justamente por ser uma modalidade com currículos e públicos diferenciados. Além disso, como corroborar as ideias trazidas nesse documento quando encontramos que ele "está orientado pelos princípios éticos, políticos e estéticos que visam à formação humana integral e à construção de uma sociedade justa, democrática e inclusiva"? (BRASIL, 2018, p. 7). Diante disso, torna-se improvável reproduzirmos o discurso de que esse documento se apresenta como democrático e para todos, já que não há sequer uma seção exclusiva e aprofundada para o público da EJA.

Voltando às modificações do ano de 2013: o programa Nova EJA é ofertado em quatro módulos - I, II, III e IV - e a disciplina de química aparece no módulo II, com quatro tempos de aula, e no módulo IV, com três tempos. As aulas são presenciais e ocorrem em dias da 
semana com um total de cinquenta minutos. Algumas das metas para os estudantes contidas no Manual de Orientações Nova EJA 2015 são: "aumentar as taxas de conclusão, melhorar a aprendizagem, desenvolver autoestima, desenvolver habilidades cognitivas e para o mundo social e do trabalho, aprender a aprender, aprender a fazer, aprender a ser e a conviver" (RIO DE JANEIRO, 2015, p. 6).

Por sua vez, os professores que atuam na Nova Educação de Jovens e adultos são orientados a seguir as atribuições disponibilizadas no Manual, como: "introduzir, no cotidiano escolar, assuntos de interesse e significância para os alunos; organizar e planejar aulas, de acordo com a realidade da turma" (RIO DE JANEIRO, 2015, p. 14-15).

Nessas propostas, o que se observa é que as metodologias sugeridas visam sempre à aproximação da experiência de vida dos estudantes aos conteúdos escolares. $\mathrm{Na}$ área de Ciências da Natureza, essa é, inclusive, a proposta apresentada pelos Parâmetros Curriculares Nacionais para o ensino regular, no sentido de não só dar significado aos conteúdos trabalhados, mas também de a metodologia utilizada contribuir na mediação da compreensão dos mesmos.

Na prática, porém, o que se nota é a organização do trabalho pedagógico voltado principalmente para o 
conteúdo químico propriamente dito, a partir do uso de vídeos e experimentação, como sugerido no Manual do Professor NEJA, o que até mesmo podemos considerar como um avanço, pela diversidade de recursos educacionais. Assim sendo, é possível dizer que as novas propostas apresentadas estão cada vez mais relacionadas com técnicas de ensino, remetendo a uma perspectiva curricular tradicional (SILVA, 1999). O currículo de Química concebido dessa forma acaba tornando o processo de ensino-aprendizagem dos nossos alunos por mera transmissão de conteúdos, além de ter uma visão universal, homogênea e também unitária.

Assim, o Ensino de Química na EJA se faz, de modo geral, de uma forma que não busca aproximar os alunos de sua realidade, com ausência de problematização e com maior ênfase na valorização de conceitos químicos e/ou relação fenomenológica com as atividades experimentais. Dessa forma, observamos que as propostas de aproximação do conteúdo químico com questões do contexto social e ambiental dos alunos, assim como os seus conhecimentos prévios, presentes nos documentos oficiais, não são valorizados nas práticas docentes realizadas na EJA.

No NEJA, para acompanhamento dos conteúdos em sala de aula, os alunos recebem um material didático elaborado pela SEEDUC/CECIERJ. Na disciplina de química, no módulo II, são apresentados conteúdos de 
Química Geral e somente um conteúdo de Físico-Química e, no módulo IV, conteúdos de Físico-Química e Orgânica. O programa Nova EJA ainda não possui um currículo específico para a química, como é encontrado no Ensino Médio Regular. Devido a isso, os professores são orientados a seguir esse material didático, que possui diversas propostas/possibilidades para que os conteúdos sejam trabalhados com suas turmas. Contudo, o material didático disponível encontra-se com os conteúdos um pouco distantes do cotidiano dos alunos, além de apresentá-los bem próximos ao currículo mínimo do Ensino Médio Regular, em alguns momentos (ALVES, 2016). Não estamos aqui defendendo a proposta para o Ensino de Química no NEJA, mas descrevendo como ela chegou até nós professores.

Assim, além da dificuldade de se trabalhar tantos conteúdos em pouco tempo, na prática, observamos um distanciamento desses conteúdos da realidade dos alunos. No material que nos é fornecido, a proposta está mais inserida na apresentação de determinados conceitos e sua relação com temas mais gerais como: protetor solar, água, efeito estufa, numa tentativa mais de ilustração do que contextualização (OLIVEIRA, LUIZA et al, 2015).

Nesse sentido, pensar a realidade socioambiental pode trazer para o ensino aprendizagem de química uma possibilidade para que o conhecimento dessa ciência permita não somente a compreensão, mas a possibilidade 
de intervenção na mesma. A discussão da temática se faz urgente dado o contexto atual marcado por calamidades, como falta de água, poluição, pobreza, dentre outros. A amplitude da questão implica que todos os setores da sociedade se envolvam no sentido de mobilização para o enfrentamento da crise socioambiental atual.

Sendo assim, a escola enquanto lócus de formação precisa se inserir como espaço de intervenção a partir das suas práticas. Acreditamos, desta maneira, que um possível caminho para contribuir com a ampliação dos conhecimentos e da consciência das pessoas, assim como para tornar o Ensino de Química mais significativo, é sua interlocução com as questões socioambientais, principalmente aquelas relacionadas à realidade concreta dos educandos (FREIRE, 2002).

Nesse contexto, nós nos questionamos: "como podemos aproximar o Ensino de Química do cotidiano dos alunos pensando na interface com o ambiente?".

Acreditamos que o Ensino de Química pode contribuir para a construção de conhecimentos que permitam o entendimento da realidade e a intervenção sobre ela, a partir da contextualização e da interdisciplinaridade inerentes a essa interlocução.

Assim, na pesquisa desenvolvida durante o mestrado profissional, no Programa de Pós-Graduação em 
Ensino de Ciências da Natureza, da Universidade Federal Fluminense, tivemos por objetivo elaborar uma proposta de ensino que pudesse ser inserido na EJA, com vistas a contribuir para a aproximação do Ensino de Química da realidade socioambiental dos alunos, que resultou na elaboração do produto educacional.

Neste estudo, temos por objetivo relatar os caminhos percorridos para elaboração desse produto, intitulado "Sugestões de abordagem da temática ambiental no currículo da Educação de Jovens e Adultos”2.

\section{Desenvolvimento}

O produto educacional resultante da pesquisa realizada no mestrado foi concebido a partir da observação da prática profissional do primeiro autor e atrelado a uma questão de pesquisa. Inicialmente, para sua elaboração, foi necessário tecer reflexões com base em referenciais teóricos e teóricos-metodológicos, de questões afetas à educação para o ambiente, à prática educativa e à Educação de Jovens e Adultos no Brasil.

Material disponível no Repositório da UFF, com acesso em: https://app.uff.br/riuff/handle/1/13861. 
No tocante à Educação Ambiental, buscamos apoio em autores da perspectiva crítica, tais como: Guimarães e Fonseca (2012); Layrargues (2000); Loureiro (2003); Tozoni-Reis (2006), dentre outros. A Educação Ambiental Crítica caminha paralelamente ao Ensino de Ciências, que tem como pressuposto a formação de um cidadão crítico e transformador, que esteja em plena consciência de que deve estar ativo na sociedade, como já discutia Paulo Freire.

Acreditamos que nós, professores, precisamos estar em busca de uma educação na qual o indivíduo seja autor de sua própria trajetória, que seja, de fato, emancipatória e não bancária, como apontava Freire. Nas palavras de Tozoni-Reis, essa educação crítica e também transformadora

[...] exige um tratamento mais vivo e dinâmico dos conhecimentos, que não podem ser transmitidos de um pólo a outro do processo, mas apropriados, construídos, de forma dinâmica, coletiva, cooperativa, contínua, interdisciplinar, democrática e participativa, pois somente assim pode contribuir para o processo de conscientização dos sujeitos para uma prática social emancipatória, condição para a construção de sociedades sustentáveis. (TOZONI-REIS, 2006, p. 97).

Nesta perspectiva, o Ensino de Química, a partir da educação para o ambiente, tem a possibilidade de 
"promover uma maior integração entre os aspectos econômicos, sociais e culturais com os aspectos ecológicos, configurando-se, portanto, uma abordagem integradora e socioambiental" (LAYRARGUES, 2000, p. 7), em que essa abordagem socioambiental demanda conhecimentos para compreensão e busca de soluções para as questões reais.

O produto elaborado foi pensando e desenvolvido, portanto, dentro da ótica da inserção da temática ambiental pelo viés transformador-crítico, pois tal ótica

Objetiva promover ambientes educativos de mobilização dos processos de intervenção sobre a realidade e seus problemas socioambientais. As ações pedagógicas devem superar a mera transmissão de conhecimentos ecologicamente corretos.... No entanto, superar essa tendência não significa negá-las, mas apropriá-las ao contexto crítico que pretendemos no processo educativo (GUIMARÃES, 2004, p. 31).

Esse ponto indicou também a necessidade de refletir sobre questões teórico-metodológicas das práticas educativas. Isso nos aproximou das discussões sobre contextualização, que vem gerando muitos equívocos entre professores e até mesmo em trabalhos publicados em revistas, justamente porque o que se constata são referências apenas ao cotidiano (COSTA-BEBBER; MALDANER, 2011). Com isso, a contextualização acaba 
sendo somente "relacionada a aplicações do conhecimento químico, ou seja, concepções sobre contextualização como exemplificação e ilustrações de contextos para ensinar o conteúdo de química" (WARTHA; FALJONIALÁRIO, 2005, p. 88).

Nosso foco na elaboração desse produto foi com uma formação de jovens e adultos que possibilite um entendimento da realidade socioambiental, tendo por base a construção de conhecimentos numa perspectiva mais integradora, na qual conhecimento científico, ambiental, cultural, tecnológico, dentre outros, possam contribuir para (re)posicionamento dos sujeitos frente à realidade.

Entendemos que a compreensão dos conceitos químicos pelos alunos possibilita sua interação com o mundo, já que, por meio desses conceitos, poderão se relacionar e compreender melhor a realidade na qual vivem. Vygotsky (2001) discute que essa interlocução favorece a construção do conceito científico que se dá de forma descendente, isto é, mais concreta, enquanto que os conceitos cotidianos ou espontâneos se desenvolvem de forma ascendente, para formas cada vez mais elaboradas, ou de maior abstração. Nesse sentido o Ensino de Química, como é apontado pelo $\mathrm{PCN}^{+}$deve, portanto,

[...] possibilitar ao aluno a compreensão tanto dos processos químicos em si, quanto da construção de um conhecimento científico em estreita relação com as aplicações 
tecnológicas e suas implicações ambientais, sociais, políticas e econômicas. [...] julgar com fundamentos as informações advindas da tradição cultural, da mídia e da própria escola e tomar decisões autonomamente, enquanto indivíduos e cidadãos (BRASIL, 2000, p. 87).

Essa perspectiva aproxima, portanto, as práticas de ensino-aprendizagem de química de uma proposta contextualizada conforme defendida por educadores químicos3, entendendo contexto, é claro, para além da simples ilustração, já que, de fato, este deve ser o ponto de partida e o ponto de chegada do trabalho pedagógico.

Conhecer um pouco da história da EJA, suas principais iniciativas políticas e programas criados, a importância dos estudos e pensamentos de Paulo Freire e como sua metodologia inovadora contribuiu para o conhecimento de uma educação problematizadora e não bancária, foi necessário para se compreender o contexto da EJA no Brasil. O recorte histórico realizado nos apontou a fragilidade que perpassa essa modalidade de ensino em nosso país, em que muitos dos programas tiveram sua extinção e/ou criação devido a interesses políticos e econômicos, e muitos deles buscavam somente o fim da erradicação do analfabetismo, omitindo, assim, uma con-

3As propostas contextualizadas foram feitas pelos trabalhos de educadores químicos como Costa-Beber e Maldaner (2011); Wartha e Faljoni-Alário (2005). 
tinuidade de estudo para os alfabetizados. Assim, considerando as especificidades da educação de jovens e adultos, entendemos que metodologias de ensino que desconsideram o contexto social e o cotidiano dos sujeitos poucos podem contribuir para construção de conhecimentos científicos. Alguns dos autores que nos deram suporte nesse ponto da pesquisa foram Gentil (2004), Strelhow (2010), Freire (2002, 2007) e Mendes, Amaral e Silveira (2011).

Num segundo momento, já com uma melhor base teórica e teórico-metodológico, debruçamo-nos sobre o levantamento e a análise da presença da temática ambiental nos principais documentos que trabalharam/trabalham com a Educação de Jovens e Adultos no estado do Rio de Janeiro. São eles: a Reorientação Curricular, proposta em 2006; o Currículo Mínimo para a EJA, apresentado em 2013 e o Material do Professor produzido para o NEJA em 2013.

Embora a pesquisa tenha sido realizada antes da publicação da BNCC e as diferentes modalidades de ensino no Brasil ainda discutirem como se colocar essa nova organização curricular em prática, cabe aqui destacar que, apesar das competências e habilidades definidas para cada ano de escolaridade ressaltarem a importância de se compreender "fenômenos naturais e processos tecnológicos" (BRASIL, 2018, p. 553) associados aos conteúdos 
de Ciências Naturais, a Educação Ambiental é apenas citada neste documento em cumprimento à legislação.

O tratamento de dados foi realizado pela Análise Textual Discursiva (ATD) por meio das discussões identificadas nos trabalhos de Moraes (2003), Moraes e Galiazzi (2006). A ATD é um processo no qual o sujeito desconstrói e logo depois reconstrói um conjunto de ideias que irão, posteriormente, possibilitar novos entendimentos sobre os discursos a serem analisados. Inicialmente, é feita a desmontagem dos textos (corpus). Aqui, temos o primeiro processo da ATD, conhecido como unitarização, caracterizada como uma leitura profunda e cuidadosa dos dados que serão analisados. No âmbito geral, é feita uma fragmentação dos textos escolhidos e, por fim, a produção das chamadas unidades de significados ou unidades significativas.

A segunda etapa é o processo de categorização ou categorias temáticas, no qual as unidades de significados acabam sendo reunidas de acordo com suas semelhanças semânticas, ou seja, existe um estabelecimento de relação entre as unidades de significados, com o intuito de combiná-las e classificá-las e formar, portanto, as categorias, que podem ser definidas a priori ou a posteriori. Por fim, na última etapa, temos a comunicação, em que são elaborados textos descritivos e/ou interpretativos a respeito das categorias temáticas, os quais são chamados de metatextos, pois "são constituídos de descrição e interpreta- 
ção, representando o conjunto um modo de compreensão e teorização dos fenômenos investigados" (MORAES, 2003, p. 202).

No estudo, optamos por trabalhar com categorias estabelecidas a priori, tendo em vista que pretendemos uma formação de jovens e adultos que possibilite um entendimento da realidade socioambiental, tendo por base a construção de conhecimentos numa perspectiva mais integradora, em que conhecimento científico, ambiental, cultural, tecnológico, dentre outros, possam contribuir para (re)posicionamento dos sujeitos frente à realidade. Esta perspectiva aproxima as práticas de ensinoaprendizagem de química de uma proposta contextualizada, conforme preconizada em documentos oficiais.

Dessa forma, o estudo foi recortado pelas categorias contextualização e conceitos químicos, e tem em vista que a inserção da dimensão ambiental na prática educativa é uma forma de desenvolver propostas de ensino contextualizadas. Esta análise teve como pano de fundo a temática ambiental. Assim, entendemos contextualização, uma das categorias de análise neste estudo, na perspectiva da dimensão ambiental, como uma prática de mediação que toma questões da realidade socioambiental; local e/ou global, tomados nos seus diferentes aspectos político, econômico, ambientais, dentre outros, como norteadora da construção de conhecimentos. 
Além disso, considerando que "o pensar e o agir com maior sabedoria sobre o mundo real e tecnológico são possíveis pela significação conceitual, pela mediação de uma linguagem muito especial, que constitui o conhecimento científico" (COSTA-BEBER; MALDANER 2011, p. 2), tomamos também como categoria de análise os conceitos químicos, com o objetivo de compreender como esses conhecimentos contribuem para o entendimento da questão proposta.

$\mathrm{Na}$ análise desses materiais, identificamos que, em todos os documentos, a dimensão ambiental se faz presente. Entretanto, o entendimento de contextualização que permeia esses documentos reflete nas possibilidades de mediação para construção de conhecimentos químicos afetos ao tema ambiental, aproximando muito mais essas práticas do viés conservador de educação ambiental do que da perspectiva crítica.

Os conceitos químicos necessários para o entendimento de temas ambientais, nosso foco de estudo, surgem nesses documentos, na maioria das vezes, somente para exemplificar situações que ocorrem no dia a dia dos alunos, sem ao menos serem utilizados para problematizar as questões. Desta forma, surgem no cenário escolar não para possibilitar uma compreensão da realidade dos alunos, mas com o intuito de fazer com que sejam mais facilmente memorizados ou ainda com a compreensão de 
que apenas apontar fenômenos do cotidiano seja suficiente para apropriação conceitual.

A abordagem tradicional do ensino de ciên-
cias que privilegia os conteúdos, há muito
vem sendo criticada por sua limitação ao
trabalhar o conhecimento cientifico, uma
vez que nesta visão a ciência é expressa de
forma descontextualizada e acrítica, de
forma que os alunos são induzidos a me-
morizar informações sem compreender o
seu significado e sua importância no âmbi-
to da vida cotidiana, ignorando assim a re-
lação ciência-tecnologia-sociedade, contra-
riando as preocupações atuais relacionadas
com a formação de indivíduos conscientes
(ROEHRIG; ASSIS; CZELUSNIAKI, 2011,
p. 11).

É importante salientarmos que, de todos os documentos analisados, somente a Reorientação Curricular "tenta", em alguns momentos, uma aproximação da compreensão da realidade ambiental dos alunos por meio dos conceitos químicos. Assim, no tocante à temática ambiental, é necessário que possamos repensar melhores estratégias e metodologias para o Ensino de Química na EJA, de modo a favorecer ao aluno o seu desenvolvimento e propiciar efetivas possibilidades para atuação em sua realidade

Assim, identificamos a insuficiência de uma proposta de ensino que possibilite a inserção de questões ambientais com um viés transformador, no qual o aluno 
possa identificar a Química na sua vivência e ampliar a sua compreensão sobre a realidade ambiental.

Em seguida, após a análise dos dados levantados, nós nos debruçamos na confecção do produto educacional propriamente dito. Para isso, buscamos levantar propostas que aproximam o Ensino de Química da questão ambiental por meio de consultas às obras de Santos e Mól (2013), Mortimer e Machado (2013), além de trabalhos como o de Auler (2007), entre outros. Ao realizarmos a leitura desses materiais, construímos temas que tivessem vínculo com os conteúdos do programa Nova EJA (NEJA), em vigor desde 2013, e que fizessem articulação com a temática ambiental.

Assim, propusemos temas ambientais pertinentes à vivência dos alunos, além dos conteúdos de química, de forma contextualizada, que possibilitem uma problematização dentro da EJA, por um viés transformador-crítico. É importante ressaltarmos que esses temas propostos são uma opção para a construção de conhecimentos científicos de forma articulada com a sua realidade ambiental local, pois acreditamos que, quando a sugestão de abordagem é contextualizada com essa realidade, ela possibilita a construção desses conceitos científicos num contexto definido, dando sentido a conceitos espontâneos dos alunos. 
Dessa forma, o produto educacional resultante da pesquisa foi constituído, inicialmente, com uma fala direcionada ao professor, apontando sua produção e inserção na prática educativa. Sua estrutura contém:1. Um breve entendimento sobre contextualização; 2. A importância da inserção da temática ambiental pelo viés transformador-crítico e a função do conceito químico nesse contexto; 3. A organização dos conteúdos programáticos do NEJA por temas geradores de problematização da realidade; 4. A problematização (situação problemas/reais), construção de conceitos articulados com as questões levantadas, novas compreensões e 5. Algumas indicações de leituras.

Em cada um dos temas, apontamos sugestões que buscam aproximar os conteúdos de química à vivência dos alunos. Os quatro temas ambientais escolhidos foram: Tratamento e a Distribuição da Água; Qualidade do Ar; Queima de Combustíveis e os Meios de Transportes e O Tratamento e o Destino de Resíduos Sólidos, por acreditamos que eles possibilitem a todos os sujeitos envolvidos no processo de ensino-aprendizagem momentos de reflexão por meio da problematização da realidade do entorno escolar, do bairro, do município e da realidade de outros locais dos alunos.

Dessa forma, esses temas devem ser utilizados como forma de ampliação do conhecimento sobre a reali- 
dade socioambiental e de construção de conteúdos químicos.

Ressaltamos que, no produto, é sugerido que esses temas sejam utilizados em diferentes momentos ou mesmo em mais de um momento, já que sua organização não foi realizada pelos conteúdos que compõem cada um dos módulos do NEJA. Assim, nele, são apresentadas sugestões de conteúdos e as estratégias que podem ser contempladas em cada um dos temas, devendo nós professores, escolhermos dentro de cada conteúdo os conceitos mais relevantes para o entendimento das situações propostas (Quadro 1) 
Quadro 1: Principais conteúdos programáticos associados aos temas ambientais

\begin{tabular}{|c|c|c|c|}
\hline $\begin{array}{c}\text { O Tratamento e } \\
\text { a } \\
\text { Distribuição da } \\
\text { Água }\end{array}$ & $\begin{array}{l}\text { Qualidade do } \\
\qquad \mathrm{Ar}\end{array}$ & $\begin{array}{l}\text { Queima de Com- } \\
\text { bustiveis } \\
\text { e os Meios de } \\
\text { Transportes }\end{array}$ & $\begin{array}{l}\text { O Tratamentb o o } \\
\text { Destino de Resi- } \\
\text { duos Sólidos }\end{array}$ \\
\hline 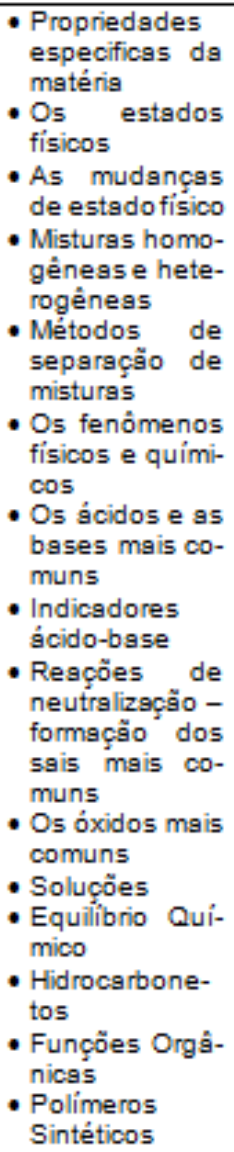 & $\begin{array}{l}\text { - Os ácidos mais } \\
\text { comuns } \\
\text { - Indicadores } \\
\text { ácido-base } \\
\text { - Reações de } \\
\text { neutralizaçäo- } \\
\text { formaçäo dos } \\
\text { sais mais co- } \\
\text { muns } \\
\text { - Reação de } \\
\text { combustão } \\
\text { - Os óxidos mais } \\
\text { comuns } \\
\text { - Hidrocarbone- } \\
\text { tos }\end{array}$ & $\begin{array}{l}\text { - Misturas homo- } \\
\text { gếnease hetero- } \\
\text { gếneas } \\
\text { - Métodos de } \\
\text { separaçäo de } \\
\text { misturas } \\
\text { - Os fenómenos } \\
\text { físicose químicos } \\
\text { - Representaçäo } \\
\text { dos fenómenos - } \\
\text { equaçäo química } \\
\text { - Estequiometria } \\
\text { - Os óxidos mais } \\
\text { comuns } \\
\text { - Os ácidos e as } \\
\text { bases mais co- } \\
\text { muns } \\
\text { - Indicadoresácido- } \\
\text { base } \\
\text { - Termoquímica } \\
\text { - Reaçäo combustäo de } \\
\text { - Hidrocarbonetos } \\
\text { - Funçöes Orgâni- } \\
\text { cas Oxigenadas } \\
\text { Polímeros Sintéti- } \\
\text { cos }\end{array}$ & $\begin{array}{l}\text { - Misturas homo- } \\
\text { gênease hete- } \\
\text { rogéneas; } \\
\text { - Métodos de } \\
\text { separaçäo de } \\
\text { mistura; } \\
\text { - Fenômenos } \\
\text { físicose quími- } \\
\text { cos; } \\
\text { - Oxidaçäoe } \\
\text { reduçáo } \\
\text { - Equilíbrio quí- } \\
\text { mico } \\
\text { - Polímeros } \\
\text { - Métodos de } \\
\text { separaçäo } \\
\text { - Hidrocarbone- } \\
\text { tos } \\
\text { - Polímeros } \\
\text { Sintéticos }\end{array}$ \\
\hline
\end{tabular}

Fonte: Elaborado pelos autores 
Para cada um dos temas, são ainda apresentadas diferentes sugestões de abordagem da temática e os conteúdos que podem ser articulados para que, nós professores, possamos escolher o(s) mais adequado(s) para a prática de Ensino de Química pretendida.

\section{O tema “O Tratamento e a Distribuição da} Água” busca favorecer o reconhecimento da importância do tratamento e distribuição de água no município dos estudantes e de diversos conteúdos químicos, possibilitando, assim, uma problematização que tome o contexto real do aluno.

Visando a superar uma abordagem conservacionista da crise ambiental, a sugestão é ir além das discussões sobre o gasto de água e seu desperdício ou sobre a ausência de água e problematizar a escassez, tentado, assim, identificar os motivos que levam a esse problema.

Para o tema "Qualidade do Ar", acreditamos ser importante refletir sobre as diversas fontes de poluição atmosférica, as quais são responsáveis por problemas ambientais e de saúde da população provenientes dos principais gases que contribuem para esse tipo de poluição.

O penúltimo tema, que discute sobre a “Queima de combustíveis e os meios de transportes", possibilita-nos discutir que a maior parte da energia que uti- 
lizamos é proveniente da queima de combustíveis e, ao queimarem, esses combustíveis acabam produzindo energia e sustâncias químicas e até material particulado, como os aerossóis que estão também presentes na temática de Qualidade do Ar.

Dentro do último tema - "O tratamento e o destino de resíduos sólidos" - , temos a possibilidade de discutir sobre os principais resíduos sólidos, pois, além de mostrar a questão da conscientização e de como evitar o descarte inadequado e principalmente discutir como minimizar esse impacto no meio ambiente, irá fazêlo refletir de forma consciente e crítica sobre o consumo exagerado de produtos, sejam eles eletrônicos ou não.

Cada um desses temas é seguido por sugestões para o trabalho em sala de aula de forma a articular ambiente e conceitos químicos. Além disso, indicamos que as propostas que envolvam levantamento de dados locais sejam feitas na forma de pesquisa pelos alunos ou, então, que sejam realizadas na forma de atividade em sala de aula, a partir de levantamentos e/ou reportagens trazidas pelo professor. Para isso, são indicadas fontes de consulta para levantamento de dados. Por fim, em cada um dos temas, são sugeridas e indicadas fontes de leitura complementar, bem como apontados prováveis recursos educacionais com possibilidades de incorporação na prática educativa. 


\section{Considerações finais}

O potencial de interlocução dos produtos educacionais com a escola e sua possibilidade de produzir reflexos na educação básica vem apontando para o seu entendimento como a principal produção dos programas profissionais. Esse é um tema que merece mesmo olhar mais cuidadoso e criterioso, não só para uma melhor qualificação dessa produção, mas, sobretudo, para ampliar sua viabilidade de inserção nas práticas educativas.

Para elaboração do produto educacional aqui descrito, tivemos que fazer o exercício de olhar criticamente para nosso campo de atuação profissional e, a partir dele, tecer reflexões teórico-metodológicas que favorecem olhar novamente para este cenário e propor soluções para questões inicialmente levantadas. Esse exercício crítico, possibilitado pelos instrumentos de pesquisa, está distante de uma visão puramente tecnicista de desenvolvimento de metodologias de ensino.

Para sua elaboração, depositamos nossos estudos por meio das inquietações, dúvidas, críticas, que são oriundas de nossa vivência em sala de aula. Assim, sua confecção permitiu uma imersão em nossa prática docente de forma real, oferecendo uma contribuição mais crítica, contextualizada, para nossa formação, assim como a de nossos alunos. 
O produto educacional surge, portanto, como um material de ensino com o intuito de apoiar a aprendizagem e auxiliar o professor na mediação de suas aulas por meio de estratégias de ensino. Não tivemos aqui a intenção de fazer propostas de mudanças curriculares, mas, a partir do entendimento dos propósitos da educação ambiental crítica, apresentamos sugestões de temas que oportunizam a introdução de conceitos químicos para entendimento de questões ambientais e maior significação dos conceitos construídos.

Destacamos ainda que o produto educacional, mesmo sendo elaborado para um cenário específico, deve ter a viabilidade de poder ser reutilizado e adaptado para diversos tipos de realidades nas quais o professor se encontre. Procuramos, então, apontar no material, alternativas para sua aplicação em diferentes contextos, ampliando sua abrangência.

Dessa forma, embora cientes da relevância do produto educacional, acreditamos que a maior produção dos programas profissionais é o professor, que a partir de um referencial teórico-metodológico e da elaboração de um produto educacional tem a oportunidade de tecer reflexões outras sobre a sua prática profissional. 


\section{Referências}

ALVES, T. R. de S. Educação de jovens e adultos: sugestões de abordagem no ensino de química a partir da realidade socioambiental. 2016. Dissertação (Mestrado em Ensino de Ciências da Natureza) - Instituto de Química, Universidade Federal Fluminense, Niterói, 2016.

AULER, D. Enfoque ciência-tecnologia-sociedade: pressupostos para o contexto brasileiro. Ciência \& Ensino, Campinas, v.1, n. especial, p. 1-20, nov. 2007. Disponível em: <http://www.academia.edu/download/54267533/enfoque_ci encia.pdf $>$. Acesso em: 02 out. 2020.

BRASIL. Ministério da Educação. Secretaria de Educação Média e Tecnológica. Parâmetros Curriculares Nacionais: Ensino Médio. Parte III - Ciências da Natureza, Matemática e suas Tecnologias. Brasília, DF: MEC/SEMT 2000.

. Ministério da Educação. Base Nacional Curricular Comum. Brasília: $2018 . \quad$ Disponível em: <http://basenacionalcomum.mec.gov.br/images/BNCC_EI _EF_110518_versaofinal_site.pdf >. Acesso em: 15 out. 2020.

CANDAU, V. M. Multiculturalismo e educação: desafios para a prática pedagógica. In. MOREIRA, A. F. B.; CANDAU, V. M. (org.). Multiculturalismo: diferenças culturais e práticas pedagógicas. Petrópolis: Vozes, 2008.

COSTA-BEBER, L. B.; MALDANER, O. A. Cotidiano e Contextualização na Educação Química: discursos diferentes, significados próximos. In: Encontro Nacional De Pesquisa Em Educação Nas Ciências, 8.; Congresso Iberoamericano De Investigación En Enseñanza De Las Ciéncias, 1., 2011, Campinas. Anais [...]. Campinas, SP: Editora da Unicamp, 2011. p. 1-12. Disponível

em: 
<http://www.nutes.ufrj.br/abrapec/viiienpec/resumos/R1376 -1.pdf $>$. Acesso em: 05 out. 2020.

FONSECA, M. da C. F. R. Educação matemática de jovens $e$ adultos: especificidades, desafios e contribuições. 2. ed. Belo Horizonte: Autêntica, 2007.

FREIRE, P. Pedagogia da autonomia: saberes necessários a prática educativa. São Paulo: Paz e Terra, 2002.

Educação como prática da liberdade. 30. ed. Rio de Janeiro: Paz e Terra, 2007.

GENTIL, V. K.. EJA: contexto histórico e desafios da formação docente. In: Seminário Interinstitucional De Ensino, Pesquisa E Extensão, 8., v. 1. 2004. Disponível em: <http://www.drearaguaina.com.br/educ_diversidade/fc_eja/ Municipios/texto_para_leitura_desafios_da_eja.pdf $>$. Acesso em: 14 out. 2020.

GUIMARÃES, M. Educação ambiental crítica. In: LAYRARGUES, P. P. (org.). Identidades da educação ambiental brasileira. Brasília, DF: MMA, 2004. p. 24-34.

GUIMARÃES, M.; FONSECA, L. C. (Org.). Educação em ciências e educação ambiental: caminhos e confluências. $1^{\mathrm{a}}$. ed. Seropédica: Editora da UFRRJ, 2012. v. 1. 158p

LAYRARGUES, P. P. Educação para a gestão ambiental: a cidadania no enfrentamento político dos conflitos socioambientais. In: LOUREIRO, C. F. B.; LAYRARGUES, P. P.; CASTRO, R. S. (org.). Sociedade e meio ambiente: a educação ambiental em debate. São Paulo: Cortez, 2000. p. 87-155. 
LOUREIRO, C. F. B. Premissas teóricas para uma Educação Ambiental transformadora. Ambiente \& Educação (FURG), Rio Grande, v. 8, p. 37-54, 2003

LOPES, S. P.; SOUZA, L. S. EJA: uma educação possível ou mera utopia. CEREJA, v. 1, p. 17-19, 2007.

MARCOLAN, S. G.; MALDANER, O. A. Espaços de formação continuada de professores em escolas pequenas e isoladas: uma lacuna a ser preenchida. Química Nova na Escola. v. 37, n. 3, p. 214-223, ago. 2015. Disponível em: <http://qnesc.sbq.org.br/online/qnesc37_3/o9-EQF-0514.pdf $>$. Acesso em: 04 out. 2020.

MENDES, R. M.; AMARAL, F. A. do; SILVEIRA, H. E. da. O ensino de química na educação de jovens e adultos: um olhar para os sujeitos da aprendizagem. In: VIII - Encontro Nacional De Pesquisa Em Educação Em Ciências, 8.; I Congreso Iberoamericano De Investigación En Ensenanza De Las Ciencias, 1., 2011, Campinas. Anais [...]. Campinas, SP: Editora da Unicamp, 2011. Disponível em: <http://www.nutes.ufrj.br/abrapec/viiienpec/resumos/Ro976 -1.pdf $>$. Acesso em: 12 out. 2020.

MORAES, R. Uma tempestade de luz: a compreensão possibilitada pela análise textual discursiva. Revista Ciência e Educação, v. 9, n. 2, p. 191-211, 2003. Disponível em: <https://www.scielo.br/pdf/ciedu/v9n2/o4.pdf >. Acesso em: 10 out. 2020.

MORAES, R.; GALIAZZI, M. do C. Análise Textual Discursiva: processo reconstrutivo de múltiplas faces. Ciência e Educação (UNESP), v. 1, p. 8, 2006. Disponível em: < http://www.scielo.br/pdf/ciedu/v12n1/o8.pdf > Acesso em: 10 out. 2020 
MORAES, M. S.; CUNHA, S. dos S. da; VOIGT, J. M. R. Onde está a Educação de Jovens e Adultos na BNCC?. In: $V$ COLBEDUCA - Colóquio Luso-Brasileiro de Educação, 2019, Joinville-SC. Anais do V COLBEDUCA - Colóquio LusoBrasileiro de Educação, 2019. v. 4. p. 1-14.

MOREIRA, A. F. B. A recente produção científica sobre currículo e multiculturalismo no Brasil (1995-2000): avanços, desafios e tensões. Rev. Bras. Educ. 2001, n.18, p. 65-81. Disponível em: <https://www.scielo.br/pdf/rbedu/n18/n18a07.pdf>. Acesso em: 10 out. 2020.

MORTIMER, E. F.; MACHADO, A. H. Química. 3. ed. São Paulo: Editora Scipione, 2013. 3v.

OLIVEIRA, L.; LATINI, R.; SANTOS, M. B. P. dos.; CANESIM, F. de P. A contextualização no ensino de química: uma análise à luz da filosofia da linguagem de Bakhtin. Revista Ciências \& Ideias, v. 6, n. 2, p. 29-45, jul./dez. 2015. Disponível em: $<$ https://revistascientificas.ifrj.edu.br/revista/index.php/reci/ article/download/355/335>. Acesso em: 12 out. 2020.

RIO DE JANEIRO. Secretaria Estadual de Educação. Manual de Orientações do Nova EJA. Rio de Janeiro: SEEDUC, 2015.

- Secretaria Estadual de Educação. Reorientação Curricular: educação de jovens e adultos: livro VI. Rio de Janeiro: SEEDUC/UFRJ, 2006.

Secretaria Estadual de Educação. Resolução $\overline{\text { SEEDUC }} n^{\circ}$ 4.359, de 19 de outubro de 2009. Disponível em: <http://www.labes.fe.ufrj.br/download/?ch=da2c3247d693e7 5bboc16495f4472536>. Acesso em 16 out. 2020.

ROEHRIG, S. A. G.; ASSIS, K. K.; CZEUSNIAKI, S. M. A Abordagem CTS no Ensino de Ciências: Reflexões sobre as 
Diretrizes Curriculares Estaduais do Paraná. IV Simpósio Nacional de Tecnologia e Sociedade - Anais. Curitiba: UTFPR, $2011 . \quad$ Disponível em: <http://www.esocite.org.br/eventos/tecsoc2011/cdanais/arqu ivos/pdfs/artigos/gtoo5-aabordagemcts.pdf > Acesso em: 16 out. 2020

SANTOS, W. L. P. dos.; MÓL, Gerson de Souza. (org.) Química cidadã. 3. ed. São Paulo: Editora Nova Geração, 2013. 3 v.

SILVA, T. T. da. Documentos de identidade: uma introdução às teorias do currículo. 2. ed. Belo Horizonte: Autêntica, 1999.

STRELHOW, T. B. Breve história sobre a educação de jovens e adultos no Brasil. Revista HISTEDBR, Campinas, n. 38, p. 4959, jun. 2010. Disponível em: <https://www.academia.edu /download/56110898/1.1._historia_sobre_eja_no_brasil.pdf> . Acesso em: 12 out. 2020.

TOZONI-REIS, M. F. de C. Temas ambientais como "temas geradores": contribuições para uma metodologia educativa ambiental crítica, transformadora e emancipatória. Educar em Revista, Curitiba, n. 27, p. 93-110, jan./jun. 2006. Disponível em: https://www.scielo.br/pdf/er/n27/ao7n27.pdf. Acesso em: 02 out. 2020.

VYGOTSKY, L. S. Pensamento e linguagem. [S. l.]: Ridendo Castigat Mores, 2001. E-book. Disponível em: $<$ http://www2.uefs.br/filosofia-bv/pdfs/vygotsky_01.pdf>. Acesso em: 02 out. 2020.

WARTHA, E. J.; FALJONI-ALÁRIO, A. A contextualização no ensino de química através dos livros didáticos. Química Nova na Escola, São Paulo, v. 22, p. 42-47, nov. 2005. Disponível em: <http://qnesc.sbq.org.br/online/qnesc22/ao9.pdf>. Acesso em: 04 out. 2020. 